166 Literatura e Sociedade

\title{
ENTRE MIM E 0 QUE VEJO: UMA LEITURA DE 0 FILANTROPO
}

ANDRÉ GOLDFEDER

Universidade de São Paulo

\section{Resumo}

Este trabalho desenvolve uma proposta de leitura de $O$ filantropo (1998) ancorada na aproximação dessa ficção de Rodrigo Naves a ensaios do mesmo autor sobre obras de Jackson Pollock, Amilcar de Castro e Mira Schendel. Sugere que a incorporação de questões das artes plásticas articula-se no livro a uma reflexão acerca dos desafios impostos ao ato de experimentação intelectual do contexto histórico contemporâneo.

\section{Abstract}

This paper develops a reading of O filantropo (1998) grounded upon the confrontation of this fiction by Rodrigo Naves with essays by the same author concerning works produced by Jackson Pollock, Amilcar de Castro and Mira Schendel. It suggests that the incorporation of problems of the realm of the plastic arts is combined in the book with a reflection on the difficulties in apprehending intellectually the contemporary world.

\author{
Palavras-chave \\ Literatura \\ e artes \\ plásticas; ficção \\ brasileira \\ contemporânea; \\ Rodrigo Naves.
}


á obras que, alçando-se para fora do mundo, simplificam-no na tentativa de melhor compreendê-lo e retornar a ele de maneira renovada. Há outro tipo de obra, porém, que busca incorporar a matéria do mundo em sua própria construção e, com isso, experimenta e faz experimentar a incerteza do mundo, suas dificuldades. Em O filantropo, Rodrigo Naves parece seguir este último caminho, assim como o leitor, que, algumas páginas lidas, já depara com a questão que emerge impositiva: "o que é este livro?"; ou, mais bem colocada, "o que são estes textos?"

Ficção, poesia, conto, poema em prosa etc. Esses seriam alguns dos muitos gêneros possivelmente aventados pelo leitor que se indagasse da natureza das 38 "pequenas narrativas" - para recorrer a um termo certa vez utilizado pelo autor para referir-se a esses textos ${ }^{1}$ - que compõem o livro de Naves. Porém, nessa indecisão de gêneros reside apenas o começo de toda a incerteza que caracterizará a experiência de leitura de $O$ filantropo. Isso, diga-se de passagem, se aceitarmos o pressuposto de que esses textos podem de fato ser lidos como um conjunto, já que a todo instante eles ameaçam revelar-se construções autossuficientes. De fato, um personagem reconhecível como o Filantropo é delineado ao longo dos textos. Porém a segurança do leitor acerca daquilo que está lendo soçobra já após poucas páginas, à medida que se justapõem diferentes (e sutis) coordenadas temporais, espaciais e, num plano mais geral, ficcionais e que a voz supostamente atribuível ao tal filantropo passa a conviver com vozes diversas, de cuja origem, feição e sentido mal podemos nos assegurar.

Isso para não mencionar a convivência dos textos construídos em primeira pessoa com outros narrados em terceira pessoa, além de relatos, semelhantes a algo como "retratos literários", que representam desde artistas significativos da arte

\footnotetext{
${ }^{1}$ Rodrigo Naves, "Introdução: o vento e o moinho", in O vento e o moinho. Ensaios sobre arte moderna e contemporânea, São Paulo, Companhia das Letras, 2007.
} 
brasileira até um ex-boxeador de interesse aparentemente nulo para o leitor, e ainda uma fábula e um texto "que tem o tom objetivo e distanciado de um hipotético catálogo de vestimentas femininas", como o descreve João Moura Jr, na orelha do livro. ${ }^{2}$ De modo que quanto mais segue a leitura, mais portos seguros da compreensão se dissolvem, a sedimentação de estruturas de sentido e a concomitante produção da dúvida a respeito dessas estruturas enfrentando-se e produzindo uma dinâmica de crescente incerteza, ao longo da qual boa parte das estruturas literárias tradicionalmente fundamentais - narrador, ponto de vista, personagem, entre outras - caem por terra. Quem fala, sobre o que fala e, no limite, se há alguma entidade que pode ser entrevista por trás de todos esses construtos aparentemente desconexos são questões que pulsam, portanto, durante toda leitura.

E esse talvez seja um ponto fundamental. Se não entregam imediatamente seu sentido ao leitor, esses textos, contudo, permitem uma leitura integrada, ainda que demandem um modo peculiar de leitura. Sua identificação por meio de títulos constituídos essencialmente por substantivos únicos ("Paris", "Linha de conduta", "Rosemiro dos Santos (1944-1991)"; a única exceção é "Daqui para frente") pode sugerir que devamos entendê-los como coisas independentes, porém, também, como coisas agenciadas por alguma espécie de instância estruturante. A determinação desta última, por sua vez, tendencialmente, mas não necessariamente associável ao personagem do filantropo (que somos tentados a identificar com o narrador) ou ao próprio autor, irá se tornar, assim, corrida a leitura, um movimento fundamental da obra. Mesmo que despiste constantemente o leitor, ameaçando confundir-se com diferentes vozes e, em última análise, ameace negar sua própria existência - não só por não se apresentar de maneira unívoca, mas também por ceder espaço a diversas vozes e a outros tipos de tratamento do material verbal -, mesmo que o faça, uma entidade que organiza essas "coisas" chama a atenção por sua estranheza e desafia o leitor a desvendar o mistério de sua natureza. ${ }^{3}$ De modo que talvez possamos falar em dois "eixos" sobre os quais se desenvolve a obra: um que percorre internamente essas narrativas, outro constituído pelas relações que

2 João Moura Jr., orelha de O filantropo, in O filantropo, São Paulo, Companhia das Letras, 1998. Todas as citações extraídas deste último livro procedem dessa edição e, pertencentes a textos, em sua grande maioria, de menos de uma página de extensão, dispensam referências em rodapé, ficando suas indicações entre parênteses e no corpo do texto.

${ }^{3}$ Essa é uma hipótese próxima a um pressuposto desenvolvido por Vilma Arêas, em ensaio sobre O filantropo, "Além do princípio da superfície: O Filantropo, de Rodrigo Naves" [disponível na internet, em <www.lusitanistasail.net/areas01.htm\#3>]. Para a autora, um resultado obtido por Naves seria suscitar a desconfiança de "que talvez não se entenda realmente o que se vê com nitidez sob a luz crua do estilo. As superfícies são polidas mas contêm pontos cegos. Além do mais, como a trama é cerrada, não podemos nos esgueirar para dentro, nos distrairmos com supostas interioridades. Erramos à tona do texto. Surge uma dúvida incômoda: será que esses reflexos nos concernem, que neles também nos miramos?". Tão amplo é o leque de questões trabalhadas pela professora em seu texto - a que só tive acesso depois de terminada a realização deste trabalho -, que não seria possível manter-me em diálogo constante com ele ao longo destas linhas, que, em alguns momentos, por sua vez, apenas contribuem com desenvolvimentos mais extensivos, a partir do prisma da aproximação de elementos da ficção de Naves com problemas trabalhados em sua crítica, de ideias já presentes no texto de Arêas. 
as vinculam. Este último revelando-se tão significativo quanto o primeiro, ou, em outras palavras, o conteúdo verbal explícito dividindo o centro da criação literária, em pé de igualdade, com a construção e atuação, vale repetir, incertas, indecisas, da vontade ordenadora que opera na obra.

\section{Linha e espaço, vontade e matéria}

Desenhos de Mira Schendel, esculturas de Amilcar de Castro e pinturas de Jackson Pollock. Tentar aproximar leituras críticas de Rodrigo Naves sobre três obras consideravelmente diversas como essas significa correr um duplo risco: de um lado, perder de vista as singularidades e a complexidade de obras e artistas, sob a pressão de seu acomodamento em formulações que generalizem forçadamente as ideias do crítico; de outro, insinuar a sistematização destas últimas em um arcabouço teórico cristalizado, possivelmente à revelia de seu sentido original. De qualquer modo, enfrentados esses riscos, tal leitura integrada poderia resultar não só numa compreensão mais acurada das formulações construídas pelo crítico, como ainda poderia fornecer pistas para a identificação de algumas de suas escolhas artísticas e de algumas questões prementes em seu pensamento crítico. Buscar elementos comuns talvez signifique, então, não um estreitamento de visão acerca das obras interpretadas, mas uma via de entrada privilegiada para a interpretação de uma obra de ficção concebida a partir de um lugar híbrido e original.

Em "Mira Schendel: pelas costas", Rodrigo Naves tenta compreender a "intensidade toda particular" apresentada pelos desenhos de Mira Schendel, indagando da razão pela qual a artista os realizava "pelo avesso do papel". ${ }^{4}$ De um lado, responde, o processo da artista seria marcado por uma diminuição do controle sobre o desenho, na contramão de todo o fundamento tradicional dessa forma de arte; de outro, as linhas que daí resultam não revelariam sua presença de maneira impositiva, e sim por meio de seu entranhamento com o papel. "Linhas inquietas, impacientes, alheias à pressa de chegar." ${ }^{5}$ Os desenhos de Schendel não consistiriam na construção de linhas que correspondessem ao resultado de gestos taxativos e decididos do artista e que se impusessem sobre o material conformando-o de maneira rígida e inequívoca. Suas linhas "mais evidenciam suas circunstâncias e condições do que se libertam delas por meio de formas que revelassem um modo certeiro de se livrar das resistências do mundo, comprometendo seus desenhos com a ordenação de um material que deveria perder sua tenacidade para que seu destino se cumprisse". ${ }^{6}$ Em suma, a presença relutante, como diz o crítico, que se apresenta nesse trabalho seria resultado dessas linhas indecisas e enfraquecidas, cuja função seria precisamente a de um "antídoto" à "vontade de ordenação presente em quase todos os trabalhos de arte". ${ }^{7}$

Algo dessa materialidade insinuante, de certa forma, insubmissa, talvez ressoe naquilo que Naves identifica como o predomínio expressivo da matéria trabalhada

\footnotetext{
${ }^{4}$ Rodrigo Naves, "Mira Schendel: pelas costas", in O vento e o moinho... op. cit., p. 266.

${ }^{5}$ Idem, ibidem, p. 267.

${ }^{6}$ Ibidem, p. 268-9.

${ }^{7}$ Idem, ibidem, p. 268.
} 
por Amilcar de Castro. Mas, se na presença marcante do papel nos trabalhos de Schendel o crítico vê principalmente a afirmação da indecisão da vontade de ordenação nesses operante, a evidenciação insistente do ferro nas esculturas de Amilcar aparece funcionando também de outra maneira: cristalizando os traços do trabalho que as construiu e remetendo continuadamente, portanto, ao entorno social rígido e estanque no qual esses gestos de certa índole construtivista e cosmopolita construíram essas obras. ${ }^{8}$ E não só o trabalho que conformou o ferro, e o passado histórico "que emperra, mais do que ordena e clarifica", ${ }^{9}$ mas também as marcas da passagem do tempo ficam evidenciadas nessas peças, cujas torções deixam à mostra as propriedades íntimas do ferro que foi moldado contra sua vontade e está fadado a enferrujar. Dificuldade e relutância, portanto, seriam os atributos fundamentais da matéria trabalhada pelo artista, donde a impossibilidade, sublinhada pelo crítico, de falar de maneira precisa em uma "expressividade do gesto" decorrente dos cortes precisos que dão forma a essas esculturas, justamente na medida em que aqueles gestos do artista enfrentam a relutância apresentada pelo material, que não se deixa domesticar totalmente.

E é precisamente aí que o autor entrevê o princípio estruturante que fundamenta essas obras: entranhadas, uma determinação formal acentuada e a resistência do material à formalização apareceriam em um estado permanente de mútua tensão. Tal como a pouca liquidez das tintas nos desenhos do artista, a oposição do ferro às torções desencadearia uma dinâmica de tensão constante entre os traços que cortam de maneira precisa o material e a presença bruta desse, que insiste em se insinuar. Enfim, as formas que daí se originam perderiam algo de sua capacidade de ordenação, tornando-se mais materiais e não se constituindo, portanto, enquanto produtos perfeitamente determinados por gestos supremos e inequívocos. Assim, em Mira Schendel, vontade ordenadora indecisa, enfraquecida e entranhamento dessa com o material. Em Amilcar de Castro, tensão entre uma vontade ordenadora rigorosa e a relutância da matéria em ser conformada de maneira taxativa. Em ambos, a problematização da vontade ordenadora que estrutura as obras, enquanto movimento fundamental da criação artística, e incorporação da resistência do material à formalização no processo de criação da obra.

Se ao falar em Pollock, contudo, Naves identifica esse mesmo polo irradiador de questões, suas leituras, por outro lado, também colocam em evidência os termos mais "drásticos" em que se teria colocado para Pollock, em comparação com os artistas que o procederam, o dilema "subjetividade-objetividade", que marcara todo o percurso da arte moderna. ${ }^{10}$ Para o artista norte-americano, não só a integridade, a potência e o grau de determinabilidade da instância que ordenaria "de fora" as obras estariam em xeque, mas também a própria possibilidade de existência de uma tal instância cuja remissão a alguma dessas noções fizesse sentido:

\footnotetext{
${ }^{8}$ Cf. Rodrigo Naves, "Amilcar de Castro: matéria de risco", in A forma difícil. Ensaios sobre arte brasileira, São Paulo, Ática, 1997, p. 235-243.

${ }^{9}$ Idem, ibidem, p. 241.

${ }^{10}$ Cf. Rodrigo Naves, "Jackson Pollock: a água-viva e o mar", in O vento e o moinho... op. cit., p. 253.
} 
Para continuar fazendo arte, ao menos do seu ponto de vista [o de Pollock], era preciso criar uma realidade que não pressupusesse a integridade de um sujeito agente - um expressionismo que, levado às raias do absurdo, rompesse com qualquer interioridade às voltas com sua exteriorização. O problema de Jackson Pollock é a rigor criar uma resistência ao próprio ato de pintar, um método que possibilitasse que as formas daí resultantes fossem a concretização da própria dificuldade de formalizar - uma recusa portanto a usar o pincel como um instrumento que domesticasse uma matéria (a tinta) apropriada a um fim (a pintura, a tela). ${ }^{11}$

Sua obra não se realizaria mais a partir de um sujeito identificado como um fluxo de expressão, o que significaria recusar a concepção da obra de arte como a realização de uma significação que fosse instituída pela interioridade de um sujeito através de sua concretização sobre alguma matéria, bem como recusar a compreensão da superfície criada pela ação como um "lugar simbólico", ou o "lugar da projeção de desejos, traumas ou figuras" - e sim como algo que "surge a posteriori" em relação à ação realizada por esse artista que pintava sem tocar nas telas. ${ }^{12}$ Espírito e matéria, a "suposta interioridade" de um sujeito e a "exterioridade da pintura"13 não constituiriam mais termos de uma possível relação de tensão e o artista configuraria sua obra justamente ao opor uma resistência ao próprio ato de expressão. O artista converte-se, portanto, em "pura exterioridade". ${ }^{14}$

De modo que a desconstrução de uma vontade ordenadora íntegra e unívoca e a exploração das resistências do material a um processo taxativo e uniforme de formalização aparecem aqui também como as questões prementes que servem de entrada às obras para Naves. Porém, no caso de Pollock, assumindo, talvez, a feição de um enfrentamento mais radical, e, de maneira análoga, assumindo desdobramentos e soluções de outro nível de desconstrução. Antes, indecisão da instância organizadora e tensão estrutural entre rigor formal e presença pungente da matéria; agora, uma vontade no limite de sua autoaniquilação, um gesto que pretende apresentar-se como um não gesto, a matéria conformando-se na obra por meio de suas próprias forças e dinâmicas: exterioridade pura.

Mas, se parassem por aí, obras e ideias estariam partidas ao meio, uma vez que o interesse de Naves por essas propostas não se atém à sua capacidade de produzir soluções originais para problemas técnicos, mas volta-se justamente para o sentido dessas soluções de colocar em ação uma problematização artística acerca de sua relação com o mundo. No ensaio sobre Amilcar de Castro isso ficava claro em alguns aspectos que já mencionei, mas vem ao primeiro plano na atenção que o crítico dá ao esforço do artista para colocá-las "em comunicação com o espaço", entre outras coisas, através da criação de certa "aragem" que habita as partes vazadas dessas obras e "torna mais generosas as trocas com o meio". ${ }^{15} \mathrm{E}$, passando do plano das soluções artísticas em si para o da sua inserção no projeto dos artistas, Naves torna ainda mais densa a discussão ao comparar tal projeto à maneira como

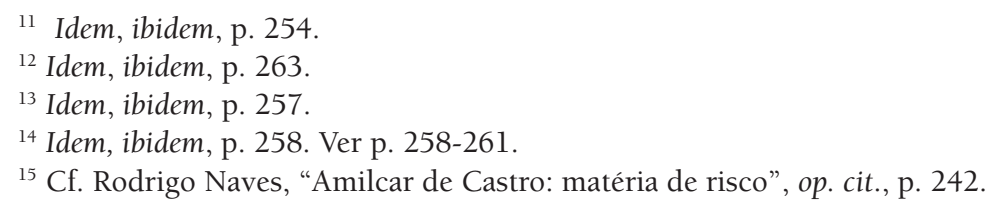


Lygia Clark e Hélio Oiticica trabalharam questões semelhantes. Os dois últimos artistas, ao tentar criar obras que superassem uma relação contemplativa entre observador e obra, desembocariam em uma "interiorização" da exploração do mundo, assentada sobre um modo intimista de experiência que se fecharia à exploração da exterioridade e do estranhamento que a experimentação do mundo por meio da criação de "espaços públicos" proporcionaria. ${ }^{16}$ Enquanto os trabalhos de Amilcar de Castro estabeleceriam uma "relação de maior altruísmo com o mundo", instaurando um "movimento de passagem":

Na obra de Amilcar de Castro o importante está em salientar a irredutibilidade da existência a vivências particulares. A arte, aí, sublinha e articula o não-artístico. A comunicação entre as coisas deve passar por um processo de diferenciação que de fato estabeleça com clareza os campos a serem postos em contato, ao invés de buscar um trânsito fluido. ${ }^{17}$

O que vai de par com o poder de algumas dessas obras de "desencadear ações generosas", que recusariam a imposição violenta de uma vontade formalizadora taxativa sobre um material. ${ }^{18}$

E aqui encontramos novamente Pollock e chegamos a um ponto decisivo dessa discussão. Em seu ensaio sobre o artista norte-americano, Naves também tinha esses últimos pontos da reflexão em conta, já ao propor entender a célebre frase de Pollock, "Eu sou a natureza", como a postura de "compartilhar o aspecto turvo da natureza, uma brutalidade infensa à clareza de significados a priori", e também ao enxergar no projeto do pintor a tentativa de produzir obras que constituíssem um tipo de materialidade que fosse de encontro com a aparência da sociedade contemporânea, chegando, pelas particularidades desses trabalhos, a objetos que devem ser entendidos como coisas que "se [opõem] às outras coisas". ${ }^{19}$ No entanto, é no momento em que se volta para a compreensão da dimensão política da obra de Pollock que o autor nos fornece um ponto de forte adensamento dessas discussões, uma vez que é aí que surge o que considero a formulação que sintetiza boa parte das ideias mais decisivas presentes nas leituras do autor acerca da articulação da problematização que essas obras operam de seu próprio modo de inscrever-se no mundo com as reflexões a que elas dão corpo no que toca ao tratamento da política, da história e das perspectivas de ação. Trata-se, enfim, daquilo que esse crítico entende como crise de inimigos, no plano de um diagnóstico acerca das particularidades do contexto sócio-histórico contemporâneo que o distanciam do "período moderno" em seu percurso até os anos 1960 e, por conseguinte, impõem a demanda de soluções estéticas que deem um passo à frente em relação às soluções anteriores da arte moderna. "O moinho não mais existe, mas o vento continua", frase de Victor Hugo apropriada por Van Gogh e que origina o título do livro de ensaios sobre arte moderna e contemporânea de Naves, seria

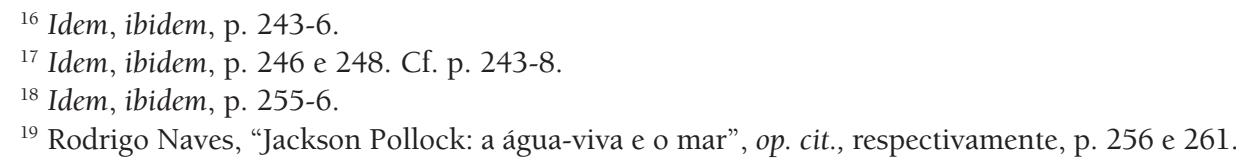


admirável, segundo ele, justamente por expor de maneira clara isso que aparece como um traço conspícuo do tempo presente: "a dificuldade de as forças sociais se articularem tanto pela ausência de um opositor claro quanto pela incapacidade de ordenarem a si mesmas, movimentos que se complicam mutuamente". ${ }^{20}$

Que a concisão da citação não deixe, entretanto, a impressão de que se está falando de um simples entorno sociológico dentro do qual a reflexão acerca das obras de arte se desenvolve, já que a intenção aqui é precisamente ressaltar a parcela dessa produção crítica em que o enlace entre essas dimensões tratadas apresenta-se com mais nitidez. Com efeito, o valor da dimensão política da obra de Pollock é atestado no ensaio por meio da avaliação da capacidade dessa obra em dar corpo pela arte à consciência daquele hiato histórico e teórico que distancia as últimas décadas do século XX do período anterior da arte moderna, este último, que tinha como referência fundamental de reflexão as ideias que giravam em torno da noção de "revolução" e da crença na possibilidade de alterações globais e multidimensionais das ordens social, política, e histórica. Parte do acerto de Pollock residiria, nesse sentido, em chegar a uma formulação artística mais adequada a um mundo no qual os horizontes de ação humana se afastariam significativamente da possibilidade de influenciar de maneira totalizante as múltiplas dinâmicas da realidade. Nas palavras de Rodrigo,

Pollock soube criar novas oposições; ao menos delinear a sua natureza. Em lugar de pressupor um enfrentamento generalizado - que sustentaria todas as ações e lhes daria finalidade -, a sua arte só obtém sentido na medida em que consegue identificar e promover oposições ao mesmo tempo em que cria um antídoto à própria univocidade de suas ações. ${ }^{21}$

E se isso traz à tona, na visão de Naves, a pergunta sobre uma "ética do presente" que correspondesse a essa percepção da vida contemporânea, volta à mente aquilo que ele identificou em Amilcar de Castro como uma "ética do risco". Certos aspectos da criação de uma parte da produção de esculturas desse artista revelariam um "pudor da unidade", que o invocaria a manter-se fiel à figura íntegra de que partiu, porém sem ater-se à reconstrução de unidades. Assim, a problematização da unidade nessas obras apontaria, junto com os elementos nelas ressaltados anteriormente, para um modo de colocar-se frente à ética e à consciência histórica que, ao mesmo tempo que descarta a possibilidade de "sobras na prática humana", que corresponderia à crença na possibilidade de uma "paciência da história de difícil confirmação", ${ }^{22}$ escapa ao fatalismo de uma concepção unitarista e trágica da história como algo fechado à multiplicidade de possibilidades em convivência, ou, digamos, à liberdade radicada na diferença e na variedade. Daí a elevação dessa "ética de risco" a uma "ética da ação", na visão de Naves, que vê nessas obras a capacidade de nos fazer "experimentar a insuficiência de nossas vivências e atos particulares na instituição do real [...], [nos fazer] ver o que está além daquilo que poderíamos

\footnotetext{
${ }^{20}$ Idem, "Introdução: o vento e o moinho", op cit., p. 15.

${ }^{21}$ Idem, "Jackson Pollock: a água-viva e o mar", op. cit., p. 261. Grifo meu.

${ }^{22}$ Idem, "Amilcar de Castro: matéria de risco", op cit., p. 256-7.
} 
acreditar uma simples extensão de nossos gestos". ${ }^{23}$ O que nos traz de volta, finalmente, à "gratuidade grandiosa" que os desenhos de Mira Schendel fariam vislumbrar, ao remeter a uma "inserção que não tolhe, mas antes libera", com a qual deparamos em momentos em que "as ações finalistas e instrumentais perdem o pé e dão lugar a atitudes não mais orientadas por uma vontade zelosa e excessiva". ${ }^{24}$

Um mesmo movimento, composto de três momentos, percorre, enfim, as questões que prendem a atenção de Rodrigo Naves quando esse se debruça sobre as obras desses artistas. Obras que colocam em xeque, por meio dos próprios processos de que são o resultado final, uma noção tradicional de "sujeito criador", cuja desconstrução se cristaliza nos trabalhos sob a forma de vontades ordenadoras problemáticas e da complexificação da relação "sujeito-matéria". Obras que se perguntam a respeito de sua própria inserção no mundo, apresentando-se não como construtos simbólicos que falem sobre a realidade de fora dela, mas como coisas que constituem um tipo de materialidade - aqui, em significação ampla - constituída também pela forma como participa do real. Por fim, a passagem do domínio da linguagem interna desses trabalhos para o de um discurso ético: a incorporação das resistências do mundo nas obras corresponde a uma consciência histórica da limitação do poder da ação do homem sobre a realidade, não assumindo uma submissão trágica, mas recusando a arrogância ilusória e simplificadora da crença em princípios de ação que pretendam dar conta integralmente da realidade. A postulação da possibilidade de uma relação de maior permeabilidade com o mundo, tanto no que toca ao reconhecimento das dificuldades e da complexidade do real, quanto na recusa da ilusão de que a arte é uma prática espiritual exterior à vida e capaz de apreendê-la de maneira onipotente. Em tempos cuja única narrativa total cogitável é a da consciência da inexistência de forças capazes de sintetizar plenamente a multiplicidade magmática de suas possibilidades e tendências, reconhecer a dificuldade do mundo revela-se uma postura mais ética do que a redução ilusória e anacrônica deste a uma matéria óbvia e entregue submissamente a nossa disposição. ${ }^{25}$

\section{A forma desmesurada}

"uma espécie de água-viva, uma coisa que se opõe às outras coisas".

(Rodrigo Naves)

Como disse, há de fato um conjunto de textos que, relacionados entre si pelo leitor, compõem um personagem reconhecível como o Filantropo. Ou, pelo menos,

${ }^{23}$ Idem, ibidem, p. 258.

${ }^{24}$ Idem, "Mira Schendel: pelas costas", op. cit., p. 270. Grifo do autor. Algumas dimensões da obra de Schendel que potencializariam suas possibilidades de aproximação com os outros dois artistas são desenvolvidas de maneira mais profunda em outro ensaio de Naves, "Mira Schendel: o presente como utopia", que não pôde ser abordado nos limites deste trabalho.

${ }^{25}$ Talvez seja interessante ressaltar que essas mesmas sistematizações aqui ensaiadas constituem nada mais que formulações, resultantes de uma abordagem peculiar, de questões e posicionamentos que o próprio crítico veicula de maneira explicita em diferentes momentos de sua produção. A esse respeito, ver, especialmente, sua "Introdução: o vento e o moinho" (ibidem, p. 117-120). 
o perfil ou algo como o retrato (somos tentados a dizer "um autorretrato") de uma figura humana compreensível dessa forma. A característica definidora do tal personagem seria a autoimposição sistemática e insistente, quase obsessiva, de princípios de regulação de sua conduta e de um sistema ético e moral minucioso, que praticamente o define enquanto ser. Como diz João Moura Jr., o que define o Filantropo é o esforço por "pautar sua existência pela justa medida aristotélica". ${ }^{26} \mathrm{O}$ Filantropo se diz comedido, incapaz de descomedimentos, em "Paris". Em "Linha de conduta", afirma: "Não descuido um só instante de minha conduta moral". Ao falar de sexo, revela-se avesso à violência, justamente por suas "conseqüências irremediáveis, a pôr em movimento forças muito superiores a nós". E prossegue: "evito em suma tudo o que coloque em risco um equilíbrio que conquistei a duras penas e que prezo mais que tudo" - serenidade, equilíbrio e autocontrole ("Sexo"). Sua preocupação com a manutenção de sua saúde ("Saúde") vem juntar-se a uma intimidade rigorosa com o trabalho metódico e disciplinado e com o desprendimento com relação à solida reputação que afirma ter alcançado ("Tarefa"). Da mesma forma, sua relação com os outros não poderia ser mais exemplar, o que fica expresso em seu peculiar gosto por dar conselhos ("Conselho"). E, lendo "Programa", não resta dúvida de sua abnegação, sua austeridade e sua integridade. Em suma, comedimento, equilíbrio, autocontrole e correção compõem o "justo caminho" que o Filantropo esforça-se constantemente em seguir. Ele diz almejar uma "humanidade harmoniosa" e julga poder realizar tal ideal impondo para si a adequação de todas as dimensões de sua existência ao seu sistema de normas, a ponto de dizer-se constantemente às voltas com uma "metafísica caseira", que implicaria decisões éticas até em lavar ou não a louça que suja.

As contradições e brechas desse "retrato", no entanto, apresentam-se logo de cara e sob as mais diversas formas. ${ }^{27}$ Já sugeri anteriormente de que forma a expectativa de se estar diante de um retrato unívoco do personagem que dá título ao livro vai se frustrando. Em um primeiro nível, com o surgimento, por exemplo, de divergências sutis em termos de localização geográfica ("Paris" é ambientado em Paris, ao passo que "Carnaval" faz remissão direta ao Brasil). Em outro, aparecem figuras que ostentam traços que as distinguem sutilmente do Filantropo, entre eles, sinais de doenças, fraqueza ou má constituição física; para depois virem textos que apresentam evidências de que os personagens que neles fala não poderiam mais ser identificados ao Filantropo, como é o caso de "Bairro", cujo narrador revela-se um homem que vive em condições materiais precárias e de maneira eminentemente desestruturada.

De qualquer modo, até aqui, o objeto das dúvidas produzidas ao longo da leitura restringe-se à natureza e ao sentido do retrato do Filantropo que vai sendo

${ }^{26}$ João Moura Jr., orelha de O filantropo, in O filantropo, op. cit.

${ }^{27}$ Optei por não incluir a sequência dos textos, tal como construída no livro, como objeto de análise. A ideia da produção de uma "dinâmica de incerteza", sugerida neste trabalho, deve ser entendida, portanto, nesse plano não linear do movimento de articulação dos textos pelo leitor ativo, que, penso, a obra pretende acionar. Já para uma esclarecedora análise das características e função do ritmo construídos nesses pequenos textos, cf. o texto já citado de Vilma Arêas. 
composto, ficando sempre no horizonte a possibilidade de que tal retrato seja estruturado não só a partir de figurações e representações, em sentido estrito, desse "protagonista", mas também do recurso a uma colagem de representações de outras figuras humanas que colaborasse para a sedimentação de uma imagem única da figura principal, que, por sua vez, poderia aparecer situada entre figuras distintas dispostas ao seu redor. Entretanto, colocados em jogo os textos que "apresentam" Anna Döring e Guignard, Rosemiro dos Santos, Mira Schendel e Eugène Varlin e o já mencionado "Mangas Cavadas", para não antecipar a discussão de outros textos de complexa significação, a dúvida assume a amplitude de uma incerteza quanto à natureza e o sentido de todo o livro. A pergunta sobre quem é o Filantropo - a apresentação stricto sensu desse revelando-se, agora, apenas um movimento operante em um complexo mais amplo - passa a ter que conviver, afinal, com a pergunta acerca da natureza da vontade ordenadora que estrutura o livro.

Em outras palavras, a incerteza relativa à natureza dessa vontade ordenadora passa a ser um movimento formal da obra tão fundamental quanto a construção substantiva da figura do filantropo. Ao justapor coisas díspares essa instância de ordenação desencadeia por si mesma uma dinâmica de concessões e restrições, em que algumas vezes entrega explicitamente o sentido das peças que articula e, às vezes, "se cala", o que, entre outras coisas, faz que se ative um jogo de ausências e presenças no qual essa entidade estruturante converte-se, em certos momentos, em um ocultamento, uma vez que a obscuridade da significação da relação supostamente existente entre algumas dessas partes leva o leitor a considerar a possibilidade de estar, afinal de contas, diante da justaposição aleatória e arbitrária dos textos. No limite de seu desaparecimento, portanto, essa vontade ordenadora parece fazer se extinguir qualquer gesto ou ato que teria ordenado a articulação de elementos. Algo das questões que estiveram na base da ideia da "pura exterioridade" de Pollock, talvez também nos desenhos de Mira Schendel, feitos pelo avesso, negando o "controle frontal do mundo" 28 parece, portanto, ressoar aqui, pois o que se vê sob ameaça em todas essas propostas é a configuração de um ato que, de fora das obras, as realiza ao projetar-se sobre algum tipo de material, realizando de maneira determinada as suas intenções. A construção do perfil do Filantropo revela-se agora parte de um complexo mais amplo, cuja estranheza se deve a sua incerteza: muitos dos textos relacionam-se por nexos de aproximação ou contraste, mas, à primeira vista, o que pode ter a ver com a figura do Filantropo um retrato de Mira Schendel ou um texto aparentemente destinado a um catálogo de roupas femininas, muito mais próximo de um objeto encontrado do que de um texto narrado?

Falando agora de outro ponto de vista, o que se realiza aqui é, também, uma problematização da unidade da obra. Constituir uma relação entre partes e todo que não dissolva a tensão entre essas duas dimensões pela submissão pacificadora das primeiras ao último também significa, como propôs Naves acerca de Amilcar de Castro, alimentar a dúvida acerca da construção de uma obra a partir de um tipo de ação que se pretende onipotente. Apesar disso tudo, ainda podemos pensar

${ }^{28}$ Rodrigo Naves, "Mira Schendel: pelas costas", op. cit., p. 270. 
na estrutura formal básica do livro como um retrato literário. Não só a sugestão fornecida pelo título constitui efetivamente uma diretriz para a compreensão da estrutura do livro, como a grande maioria dos textos consiste na apresentação de pessoas por ela próprias, sem contar a pista produzida pela pura e simples presença de um texto intitulado "Retrato", repleto de significações importantes para o livro, e que sugere, ainda que de maneira ambígua, a associação da voz de seu narrador à do Filantropo. Estaríamos falando, entretanto, de um retrato que desconstrói precisamente a ideia de integridade do sujeito - desconstrução essa que, como se verá mais adiante, constitui aspecto temático importante da obra -, ao dar forma à pessoa que quer figurar por meio da articulação de características contraditórias, a partir de perspectivas diversas e valendo-se da articulação de fragmentos construídos a partir de modos muito diversos de tratamento do material verbal. Um retrato que aponta, por isso, para o caráter problemático da expectativa acerca da possibilidade de figurar o Filantropo - ou, no limite, qualquer homem - por meio da construção de uma imagem única. No limite, enfim, um antirretrato. O sujeito, aqui, como na vida, é constituído também pelo outro.

Dito isso, talvez não seja arriscado demais afirmar que algumas das questões que prendem a atenção de Rodrigo Naves nas obras de Jackson Pollock, Mira Schendel e Amilcar de Castro reaparecem em O filantropo de maneira significativa. Não se trata, é importante ressaltar, de soluções artísticas equivalentes: a leveza e "descompromisso" que marcam a estruturação dos desenhos de Mira Schendel muito se distanciam do quebra-cabeça desmesurado de Naves; da exterioridade pura de Pollock ressoa algum tipo de "ocultamento" ocasional e estratégico, mas é difícil pensar irrestritamente em uma forma de trabalho anônimo, no limite do antiexpressivo, em um livro que é quase todo narração (ainda que com sentido subvertido); e as diferenças com relação a Amilcar de Castro seguem na mesma direção. No entanto, a desconstrução de uma vontade ordenadora unívoca, taxativa e plena permite aproximar os quatro artistas. Em Naves, o que se apresenta é essa vontade de difícil definição e que articula as partes do livro de maneira elíptica e, em certa medida, aberta, demandando do leitor, diga-se de passagem, uma atitude totalmente distinta da de um observador contemplativo, de um leitor passivo. Vontade também beirando desintegrar-se, dada a composição do texto a partir de uma pluralidade de vozes heterogêneas e, algumas vezes, aparentemente desconexas.

De tal modo que poderíamos nos perguntar também em que medida uma obra como O filantropo poderia "incorporar a resistência de seu material", o que se revela complicado, pois em literatura não há, como em pintura ou escultura, uma matéria física que tenha de ser conformada ou deformada pelo artista. Mas, de fato, na sensação de incerteza e indefinição que permeia o livro entrevê-se algo que remete a uma resistência. Afinal de contas, aquilo que resiste à linguagem não é a ausência de sentido, a opacidade das coisas, a limitação irredutível da palavra, em sua tentativa de apreensão do mundo? Com efeito, ao tornar difícil a operação de estabelecimento do sentido dos "fragmentos" e de suas articulações, nunca cabalmente definíveis, o modo de articulação deliberadamente lacônico dos textos (para não mencionar a opacidade constituinte deles próprios) traz ao primeiro plano precisamente os limites da sua própria potência de ordenar um material, 
ainda que não se trate da relutância propriamente dita dos conteúdos textuais a serem articulados, e sim da atuação de um modo de articulação que não opera a partir de princípios claramente definíveis e se recusa a preencher todas as lacunas que entremeiam os textos.

Em suma, o autor forja uma vontade ordenadora que não revela sua natureza e nenhum princípio fundamental de operação, nenhuma medida. Portanto, desequilibrada, desmesurada, descomedida. A mais completa negação da ordem que sustenta a vida do Filantropo. Daí uma tensão fundamental, altamente produtiva, que se estabelecerá permanentemente no livro, entre forma e conteúdo. Essa tensão constituindo, por outro lado, o resultado do que parece ser a solução mais original do livro, a saber, sua construção ancorada na articulação de procedimentos literários com procedimentos de extração plástica. Isso se entendermos estes últimos estritamente como procedimentos, em última instância, literários, mas configurados de maneira a incorporar algo de certas questões tratadas de modo peculiar no universo das artes plásticas, bem como algo de certas soluções criadas nesse universo, de modo a propor novas possibilidades de tratamento de funções literárias fundamentais. Essas, como resultado, se apresentarão no livro sob a forma de ruínas, rescaldo final de um movimento prévio de desconstrução, mas sobreviverão, também, transfundindo-se às custas do empréstimo dos contornos de corpos alheios: processos artísticos de extração eminentemente plástica.

Isso tudo resultando, finalmente, em um modo de composição que permite a Naves recorrer a uma forma de estruturação que, num plano não verbal, elíptico, ou "silencioso", conforma a matéria verbal da literatura de modo a reafirmar e reforçar o que foi enunciado no plano temático (por meio da interação cumulativa dos "eixos intra e intertextuais", mas não apenas) e, ao mesmo tempo, infundir conteúdo verbal e temático a fragmentos que, se fossem peças de uma escultura, por exemplo, teriam sua capacidade de enunciação restrita exclusivamente à veiculação dos significados emanados pelas propriedades de seu material e pela maneira como foram conformados e organizados. Ou, dizendo de outra maneira, a articulação de uma estruturação "plástica" com uma composição verbal potencializa tanto possibilidades literárias quanto possibilidades plásticas e resulta em uma obra que explora de maneira original e altamente profícua a interação entre as dimensões formal e temática.

\section{Figura e fundo}

Sempre tão comedido e autocontrolado em sua vida cotidiana e no trato com os outros, o Filantropo vê sua conduta se desestabilizar quando se encontra às voltas com o desejo, a paixão e o sexo. No encontro com o sexo oposto, marcado pela experimentação do acesso a um corpo alheio e da abertura do corpo próprio àquele, o rígido sistema que possibilita a soberania absoluta do espírito e da moralidade sobre os impulsos físicos e irracionais, que caracteriza a conduta do Filantropo, ameaça cair por terra. Ameaça essa expressamente reconhecida pelo personagem: o sexo colocaria em risco aquele equilíbrio que teria conquistado a dura penas, e, por isso, seria para ele "uma coisa difícil", "com que lida mal" 
("Sexo"). E irão nessa direção diversos textos em que irrompem certos tremores na conduta do Filantropo: em "Vulgar", a própria mudança repentina de tom é que dá forma a esses abalos, o tom quase sempre contido e culto cedendo espaço ao chulo: "Chamava meu pau de pica. Às vezes pedia que eu a fodesse. Outras, que a machucasse". Em "Verão" algo semelhante ocorre, o tom equilibrado usual dando lugar a um tom de súplica, característico do fervor irracional do crente desesperado, que aqui clama, rezando para Deus, que esse lhe conceda logo a senilidade, pois que não suporta mais a tentação das jovens mulheres e os "transes insuportáveis" por elas provocados. O mesmo sendo confirmado, enfim, em "Princípios", texto que parece sintetizar toda a conduta moral do Filantropo, mas, dessa vez, narrado em terceira pessoa, cujo narrador afirma ser o fato de amar perdidamente as mulheres, de maneira quase descontrolada, o elemento que abalaria a conduta regular do personagem e o desagradaria; no contato com elas, que sabia comporem "uma outra humanidade", seus princípios "não tinham efetividade". No encontro com o outro, e com aquilo que no próprio Filantropo lhe escapa ao controle, começam a se insinuar as falhas e as fragilidades do sistema que pauta sua vida tão meticulosamente.

O desejo, aquilo que por definição escapa ao controle do homem e tem o poder de lhe alterar o espírito e a ação, teria que ser domesticado de alguma maneira pelo Filantropo, que tenta fazê-lo, buscando recalcá-lo, ou tentando escapar ao seu poder arrebatador, como acontece em "Verão" e se confirma em "Princípios" ("Hoje que já não as deseja, encontrou a calma tão almejada"), mas, talvez em vão, como parece ficar sugerido na confissão da expectativa de uma paixão avassaladora em "Carnaval". Algo reverberado também em "Alvura", mas que aparece de maneira ainda mais interessante em "Altivez", no qual a possibilidade de uma experiência sexual exercida em absoluta autossuficiência, que provocaria mais a sensação da restituição da unidade da própria pessoa do que sua dissolução pelo contato com outro corpo era admirada e, possivelmente, invejada pelo narrador.

Contudo, essa ânsia pela manutenção do controle nessas situações perigosas aparece de forma mais significativa na obsessão pela ideia de higiene, presente em quase todos esses últimos textos. Em "Verão" e "Vulgar", a higiene, enquanto limpeza, asseio corporal, aparece como algo desejável, ao passo que em "De doze anos", surge como algo fundamental, precondição para a realização do ato sexual. Porém, principalmente neste último texto, ela assume uma amplitude maior, agora a constituir um valor pertencente à esfera de princípios de conduta do Filantropo e chegando a elevar-se à condição de princípio de conduta de vida. Assim, de um lado, está o caráter asséptico, protegido do contato, tal como em "Alvura"; e, de outro, um ideal que transcende o domínio físico da limpeza, integrando-se em um círculo de virtudes mais amplo, tal como se lê em "De doze anos":

De fato, a higiene é o cerne da questão. Como se sabe, também a culpa é uma forma de desasseio. [...] Convém contudo explicar mais largamente o que entendo por higiene. Limpeza? Também. Mas por certo também clareza, no sentido de saber onde temos a língua. Bom mesmo é poder ver. Isso sim é muito higiênico. [...] Só pessoas superficiais dão primazia àquilo que não vêem: donde penetrações, intercursos, palavras igualmente justíssimas. 
Nisso, tal clareza, visibilidade, exterioridade indo se juntar a outro foco de obsessão, presente em todos esses textos, a saber, as superficies. Ou melhor, a preferência pelas superfícies em detrimento dos volumes e das profundidades, primeiro naquilo que as superfícies guardam de comum com as extensões higiênicas: maiores possibilidades de controle por sua maior clareza, visibilidade e exterioridade. Mas também na medida de sua maior suscetibilidade, como se sugere em "Verão": "Volumes, Senhor, são entidades menos tentadoras: tão plenos, tão suficientes. Já superfícies não. Precisam de contato para se realizar, e aí nos perdemos".

Superfície e volume como noções-chave para a compreensão de uma obra literária? Parece ser exatamente essa a pergunta espantada que começa a se impor ao leitor. Sua surpresa se confirmando, à medida que a função central dessas noções e imagens revela-se como mais um índice da originalidade de $O$ filantropo, assim que percebemos que por meio delas um terceiro nível de leitura passa a ser ativado, compassado por um terceiro nível de princípios que estruturam a(s) narrativa(s) a partir de procedimentos criados de maneira inteligentemente nova por Naves. Entre aquele tipo de procedimento "de extração plástica", que operava sobretudo no eixo do estabelecimento de vínculos entre os textos que compõem o livro, e aqueles procedimentos mais tradicionalmente "literários", surge uma rede de imagens de extração plástica operante entre esses dois níveis, à primeira vista funcionando de maneira gratuita, com sentido insondável dentro de cada texto, mas que é articulada à medida que o leitor preenche as lacunas entre os textos e dá sentido àqueles textos que aparentemente são fragmentos desconexos e carentes de alguma razão de ser. Não mais apenas nos textos sobre sexo, desejo e paixão, mas, por toda parte, entram em cena ideias que orbitam em torno do sistema de imagens "superfície - volume" e "corpo - espaço", e que compõem uma nova camada de significação que estabelece pontes entre os diferentes níveis semânticos que, por sua vez, em sua interação, veiculam o sentido da construção da imagem do Filantropo.

Assim, o "retrato" de Mira Schendel, que, à primeira vista, aparenta dificilmente ocupar alguma "função" relevante dentro da obra, irá se articular ao resto da composição, primeiramente, por nele sobressaírem impressões acerca da constituição corporal da artista, como a necessidade que Schendel teria de estar em "lugares que dessem a seu corpo a possibilidade simultânea de afirmação e cerceamento", e que, juntas, compõem uma figura de "traços discretos, breves, mas de uma intensidade assombrosa" e que "parecia querer confundir-se com o ambiente". Algo semelhante ocorrendo também em "Mangas cavadas", este sim, texto definido precisamente pela estranheza causada pela sua primeira leitura, pela dificuldade de se encontrar sentido em tal descrição objetiva de vestimenta feminina. Porém o que se lê no meio dele é uma caracterização inesperada do que seriam axilas: "uma parte do corpo humano que está entre dentro e fora, uma região de forte transpiração, na qual a pele fina e engelhada traz à mente a idéia de metabolismo, de passagens de um lugar a outro" ${ }^{29}$ De modo que nossa atenção passa a ser conduzida à concentração nas recorrentes descrições de corpos cuja relação com o

\footnotetext{
${ }^{29}$ Grifos meus.
} 
espaço é problemática, excepcional, ou simplesmente saliente, descrições essas que constituem parte do movimento mais amplo que articula as diferentes modulações da forma de aparecimento e tratamento das mesmas ideias da passagem de um lugar para outro ou de dentro para fora e da interação de corpos com o espaço. E se, no plano do "enredo", essas ideias aparentam nada ter a ver com o "personagem central", é justamente essa aparente desconexão que revela o modo peculiar de estruturação construído por Rodrigo Naves: menos a caracterização da trajetória do "personagem principal" e a narração de sua trajetória e mais a própria estruturação incerta e desmesurada em interação com essa rede de significantes - é nisso que reside a composição de $O$ filantropo. O que o autor quer dizer fica dito não tanto pelos destroços restantes da desconstrução da ideia de enredo, e mais através do tratamento da ausência de uma vontade ordenadora unívoca e das relações "volume-superfície" e "corpo-espaço".

E, se é que faz sentido fixar temas, motivos e enredo num livro como esse, a formulação menos tolhedora da complexidade proliferante de seu tema seria: a construção de um modo de relação impermeável e absolutamente descontínuo entre corpo e espaço, homem e mundo e sua contraposição a uma relação mais permeável, contínua. Para dizer de outra maneira, O filantropo põe em movimento e dá forma literária a uma reflexão de amplo escopo e multifacetado tema, em cujo cerne está a construção e desconstrução de uma forma de existência pautada pelo afã de controle absoluto de si e do mundo a partir de princípios de conduta ou de ação unívocos e estanques e sua contraposição àquilo que Naves vislumbrava como questão presente na obra de Amilcar de Castro, o estabelecimento de uma "relação de maior altruísmo com o mundo" ${ }^{30}$ O que torna nítido, afinal, o sentido de nos perguntarmos sobre o sentido e a função de uma possível incorporação de questões e soluções "plásticas" por esse autor, que dizia, em ensaio sobre outro artista brasileiro cujas questões em parte se aproximam das dos três aqui tratados, que "A pintura moderna afastara as relações mais ou menos serenas entre espaço e objeto, entre figura e fundo. Afinal, como manter a autonomia dos seres quando tudo parece girar segundo uma única dinâmica, que a todos impõe a lógica do mercado?". No cubismo, por exemplo, diz ele, "a unidade das telas obtinha uma nova configuração, na medida em que esse intercâmbio propiciava uma interação mais estreita entre ambos", estabelecendo-se assim, "uma continuidade entre as figuras e seu ambiente, sem as antigas imunidades recíprocas" ${ }^{31}$ E o Filantropo não seria precisamente o contrário disso, algo como um corpo excessivamente demarcado, impermeável ao que se encontra em seu entorno, ou, pelos menos, algo que se pretende imune à ação do meio em que está inscrito, que se quer uma mônada autogerida e autossuficiente?

Já em "Sexo", víamos o Filantropo confessar que durante o ato sexual procura ardorosamente "achar um nexo entre superfície e profundidade". E acrescentar: "Se arfo, se me entrego ao jogo turbulento em que os órgãos se confundem, me

\footnotetext{
${ }^{30}$ Rodrigo Naves, "Amilcar de Castro: matéria de risco", op. cit., p. 246.

${ }^{31}$ Rodrigo Naves, "O Brasil no ar: Guignard", in A forma difícil, op. cit., p. 132-3.
} 
move a vontade de acesso a um corpo menos demarcado, e portanto mais pleno e surpreendente, carnal". Com efeito, a inviabilidade crônica dessa inserção hermética no mundo, fadada à permanente instabilidade, justamente porque excessivamente completa, fechada, ocupa posição crucial no livro, de forma notável, em três fragmentos que mereceriam leitura muito mais cerrada do que a que se pode realizar aqui. Em "Experiência", a incerteza quanto à possibilidade de associar seu narrador definitivamente ao Filantropo já reforça o lugar desse e dos dois outros textos no livro: trata-se de aspectos destoantes da figura total do personagem, de confissões desse acerca dos focos problemáticos de sua existência supostamente harmônica, ou de outras vozes que dão corpo a formas "mais altruístas" de fazer parte do mundo? Nesse primeiro texto, uma voz diz: "Acontece no entanto de eu me sentir variado, organizado por estratos de composição diversa, constituído de tecidos heterogêneos, de textura e consistência desencontradas. Trago então o mundo no forro, por dentro". Precisamente a forma de experiência do mundo que o Filantropo tenta recusar: a que se dá por meio de uma relação de entranhamento, que pode, ela mesma, produzir a percepção do caráter fragmentário e internamente variado do que se entende contemporaneamente por "sujeito". Como é dito no texto, uma "sensação de permeabilidade", que torna o personagem "irritadiço".

Mas é em "Luz" e "Escala" que essa dimensão chega a um ponto de adensamento impressionante. Luz, brisa e aragem aparecem aqui como as imagens- chave que caracterizam certo modo de ver. O narrador que aqui fala, em ambos os casos, diz-se sentado, de modo a indicar uma atitude contemplativa, mas - e aqui está o ponto importante - de um tipo de contemplação que pretende assimilar algo das coisas que contempla. Em "Luz" lê-se: "A luz que me falta está ali adiante [...] Ver é experimentar o que não temos, embora à nossa frente". A brisa e a aragem trariam ao personagem algo dessa luminosidade que ele diz não poder franquear, oferecendo algo de sua própria "transparência" e do seu frescor que, por sua vez, "falava das coisas suspensas e soberanas". Haveria um "lado de cá" e um "lado de lá", o personagem ficando "na soleira", "de fora" e perguntando-se "Mas como descrever o encanto de estar fora se de fora estamos?". Enfim, "luz", aqui - quase não sendo necessário lembrar o papel da luz no universo das artes plásticas, em suas diversas formas e graus em que permite à subjetividade do gesto do artista captar as coisas do mundo que reconstrói - é o que o autor mobiliza para falar de uma maneira de experimentar as coisas externas a nós, de modo a assimilarmos algo delas, fazermos parte daquilo que não é nós mesmos, o que fica claro na frase final do texto, "O que está de pé é o que ostento": ostentar, ou seja, possuir e apresentar as coisas que vivem fora de nós.

Quanto a "Escala", seria necessário deter-se mais no texto, cujo título já antecipa sua estruturação arraigada na exploração de ideias "plásticas", por meio da qual apresenta um personagem que relata sua vida em uma cidade litorânea, na qual se dedicava a contemplar o espaço da cidade ao longo de todo o dia. A paisagem da praia, aliás, contrastando, com seus contornos e limites pouco definidos, com a paisagem em que se situaria antes o Filantropo - o prédio urbano, com suas linhas retas e definidas. Aqui, de novo, a brisa, a "aragem leve", tornando o espaço e as coisas mais leves, menos definidos. E a personagem, que afirma ter ido para 
lá para "aprender a extinguir-se", chama a atenção exatamente para a "ausência de ambição da parte de seres e formas", que "engrandece ainda mais o espaço". Fazer parte do espaço, experimentar o mundo por meio de uma relação permeável, ver as coisas tornando-se parte delas é do que se fala aqui, como confirma o personagem: "Se meus olhos se detêm ali ou mais além, sinto corporalmente as mudanças de escala, expando-me, contraio-me, sou o que há entre mim e o que vejo".

Mas "ver" o mundo é também uma etapa da criação artística. E, de fato, em "Trabalhos manuais", essa forma de ação e de relação com as coisas se desdobra também em ideal artístico, quando seu narrador afirma ter decidido dedicar-se à literatura por considerá-la uma alternativa "mais prática" ao ofício de encadernador, que tentara aprender, e cuja essência considerava ser "diminuir a distância entre as coisas e exercer sobre elas um domínio rude e doce". Todavia, se é realmente correto tentar identificar no texto uma indagação acerca do sentido da atividade artística, o "ideal" que seria postulado apareceria em negativo. Pois, se de fato aparece aqui a dimensão artesanal da prática artística, não é exatamente essa forma de atividade artística que melhor se coaduna com aquela relação mais altruísta com o mundo. Bastaria, para ilustrar o que quero dizer, confrontá-lo ao que se lê em "Forma e conteúdo", conclusão do volume de ensaios reunidos de Rodrigo Naves, na qual o crítico ensaia algumas considerações acerca de sua concepção do que seria a atividade artística. Sua ênfase recai justamente na ideia de que "a grandeza da arte" residiria numa "renúncia à manipulação das coisas" e, portanto, "num tipo de percepção que também renuncie ao controle e à dominação". ${ }^{32}$ Desse modo Naves sintetiza muito de sua visão acerca dessa indagação de amplo escopo e conclui apontando para a ideia da arte como a exploração de um tipo de experiência das coisas que as retira de seu complexo normal de relações, e que se realiza, em geral, em "obras que são, simultaneamente, parte do mundo e sua recusa". ${ }^{33} \mathrm{E}$ $O$ filantropo corresponde a algo desse gênero: fala sobre certo modo de ver e se constrói realizando a experiência dessa visão; no limite, o livro é essa visão, entre o observador e as coisas, pois se realiza no material e não apesar dele.

\section{Mundo desmesurado, forma descomedida}

"um mundo tragicamente desmesurado e no entanto feito à nossa medida".

(Rodrigo Naves)

Na verdade, uma maneira de ler a "história" contada em O filantropo é entendê-la como a história do declínio desse personagem. Os movimentos que compõem a imagem do filantropo são entremeados ao longo de todo o livro pelos movimentos que compõem seu esboroamento, que postulam a inviabilidade da sua existência. Ora, se seu retrato é construído também por imagens de outros, assim também o será o retrato de sua decadência. Já por volta do décimo texto,

\footnotetext{
32 Rodrigo Naves, "Conclusão: forma e conteúdo", in O vento e o moinho, op. cit., p. 508.

${ }^{33}$ Idem, ibidem, p. 508-9.
} 
relatos de fraqueza física ou doença começam a irromper em meio à descrição que o Filantropo faz de sua vida equilibrada, próspera e saudável. Em "Caráter", uma voz anuncia-se com os dias contados. E é notável que um elemento que possibilita a aproximação dos quatro retratos stricto sensu feitos no livro e que é ressaltado neles, de maneiras diferentes, é a morte de quase todos os retratados por causas que lhe escaparam totalmente ao controle (Mira Schendel e Anna Döring faleceram em consequência de câncer e Rosemiro dos Santos baleado em um ônibus após esmurrar um homem que assaltara sua mãe). ${ }^{34}$ Essa ideia sendo reforçada, afinal, em "Aventura", um dos últimos textos na sequência do livro, que a essa altura está permeado muito mais pelas contradições e problemas crônicos da existência do Filantropo do que por sua descrição positiva. Nesse fragmento lê-se: "Uma bala atravessou minha carne um pouco acima da cintura. Faz dois dias. Não sei o que pensar desse acaso. Passar diante de uma loja, ser ferido por uma bala perdida".

A morte do Filantropo, em termos literais, não é física. Esses outros retratos só fazem reforçar o esboroamento de seu modo de existir, sua "morte moral", poderíamos até dizer, que se decreta no penúltimo fragmento do livro, "De doze anos". Aqui, todos os ideais, medidas e normas que pautam aquela existência são cínica e ironicamente aplicados na relação sexual com uma menina de doze anos de idade. "Porque a ausência de pêlos pubianos, uma expressão das mais felizes, não apenas torna a operação mais higiênica, como também afasta de vez qualquer possibilidade de culpa", começa o Filantropo. E termina, "elas se tornam impacientes quando ultrapassamos a justa medida".

A inviabilidade do Filantropo está em sua recusa à aceitação das resistências do mundo. O Filantropo quer domesticar o mundo, colocá-lo numa redoma e manuseá-lo com absoluto controle. Esse é o caráter da sua relação com as mulheres, asséptica, obsessivamente higiênica, o desejo aparecendo com algo perigoso, e a senilidade, com sua suposta inapetência para a paixão física, como um alívio. O mesmo para sua relação com sua vida cotidiana, e com o tempo ("Vigília"; "Programa"). No mesmo sentido, ele se quer um ego uno, íntegro e indivisível; sua recusa estende-se também, portanto, ao reconhecimento do caráter fragmentário e múltiplo do sujeito, bem com a constituição parcial desse pelo contato com a alteridade. Quando se vê inquestionavelmente partido, ou atravessado por forças que o superam, confessa-se incomodado ("Experiência"), tenta evitar essas forças ("Verão") ou acredita ilusoriamente dominá-las ("Programa"). Ele é (ou deseja ser) como que um corpo excessivamente demarcado, com contornos absolutamente definidos e, por isso, impermeável ao mundo que o contém. O que significa que recusa o mundo, que, no limite, não o experimenta efetivamente. "Bom mesmo é poder ver", dizia o Filantropo. "Ver e não experimentar, ver e não fazer parte", seria possível acrescentar. Comedimento, aqui, se aproximando, assim, de

\footnotetext{
${ }^{34}$ A morte de Eugène Varlin, à primeira vista, uma exceção, embora decorrente do ato desse de entregar-se voluntariamente às forças de reação à Comuna de Paris, corrobora essa linha de leitura: pode ser entendida como o sucumbir da vida de um homem à força esmagadora de uma situação objetiva.
} 
seu significado original: "medir". E medidas também são isso: instrumentos humanos que reduzem a complexidade do mundo e convertem-no em algo manipulável pelo homem. Talvez, então, filantropia assuma aqui um sentido irônico, também mais próximo de seu sentido mais literal, "amor à humanidade", porém, subvertido: amor excessivo pelo homem, crença cega na vitória do homem sobre o mundo.

Ao comparar os desafios históricos enfrentados pela arte moderna produzida até os anos 1960 àqueles enfrentados pela arte posterior a esse último período, Naves celebra a concepção de um ideal de arte que operasse por meio da experimentação do mundo: a arte moderna não apenas revelaria a complexidade do processo sócio-histórico em que se inseria, mas "ajudava a afirmar sua vitalidade, ou seja, a enorme capacidade de produzir alternativas, de criar formas que ajudassem a experimentar o mundo como algo permeado por alternativas e possibilidades". ${ }^{35}$ Agora, no contexto presente, para a "ética da ação" da arte, experimentar o mundo deverá significar também enfrentar a dificuldade de determinar grandes matrizes de pensamento e de conhecimento e ordenação do real. Talvez vá nessa direção a concepção da construção de O filantropo, que, mais do que falar sobre a dificuldade do real, produz uma experiência de incerteza e dificuldade ao produzir a si própria. O movimento triplo que Naves delineava na obra de Schendel, Castro e Pollock está no bojo de sua ficção. Algo que, por outro lado, é possível graças à concepção peculiar desse projeto que, ao compor uma obra que, entre outras coisas, opera por meio do tratamento literário de questões desenvolvidas por meio de sua interação em diferentes ordens de procedimentos e de estruturação literária, chega a um livro dotado de um poder ímpar de significação. Quer dizer, o alcance das formulações do livro resulta em múltiplas possibilidades de sentido, o que remete O filantropo a certa propriedade fundamental da obra de artes plásticas, que, construindo um conjunto único e simultâneo de enunciados, podem ativar a reverberação de diversas camadas de significado. Os mesmos gestos que contrapõem aqueles dois modos de pertencer ao mundo dão conta de falar sobre a condição do sujeito, das experiências histórica, política e ética e permitem anunciar e realizar uma concepção de arte compassada com a concepção de uma "ética do presente" peculiar.

O moribundo que se apresenta em "Aventura" talvez forneça, assim, a imagem derradeira do Filantropo, quando diz: "as faixas com que envolvi meu tronco cheiram mal. Sinto que apodreço. Se ando, é para ver se disperso esse odor acre [...] Devo morrer em breve". O Filantropo também carrega algo de podre, algo em vias de morrer, pois sua existência revela-se inviável. Ou talvez carregue somente restos em decomposição de uma suposta realidade passada. É possível, então, que não seja absolutamente inviável. Que sua imagem seja, afinal, um retrato descomedido de uma época desmesurada, antídoto contra ações ingenuamente filantrópicas.

\footnotetext{
${ }^{35}$ Rodrigo Naves, "Introdução: o vento e o moinho", op cit., p. 16.
} 